\title{
The Tobacco Control Scale as a research tool to measure country-level tobacco control policy implementation
}

\author{
Ariadna Feliu ${ }^{1,2,3,4}$, Esteve Fernández ${ }^{1,2,3,4}$, Antoni Baena ${ }^{1,2,5}$, Luk Joossens ${ }^{6}$, Armando Peruga ${ }^{2,4,7}$, Marcela Fu ${ }^{1,2,3,4}$, Cristina \\ Martínez $1,2,4,8,8$
}

\section{ABSTRACT}

InTRODUction The Tobacco Control Scale (TCS) was designed for advocacy purposes but has also been used as a research tool. In the present study, we characterized TCS use, its limitations and strengths, and critically assessed its use as a research instrument.

METHODS We conducted an extensive search of the biomedical databases PubMed and Web of Science for the keyword 'tobacco control scale' in all fields. The search was limited to studies published in the period March 2006 to December 2019. Out of 69 hits, 32 studies met the inclusion criteria. Two reviewers independently extracted information from each publication regarding their general characteristics, publication and research aspects, and the characteristics of the use of the TCS.

RESULTS We found that researchers have used the TCS as a tool to monitor tobacco control policies mainly in cross-sectional observational studies with ecological and multilevel designs directed to advocacy and the promotion of further research. Different outcomes, such as smoking prevalence and quit ratios, have been associated with tobacco control policy scores. The main reported limitations of the TCS were a low variance across countries and a failure to express enforcement and to incorporate the most recent legislation.

CONCLUSIONS The TCS has been commonly used to assess differences in outcomes according to tobacco control policies. However, there are still areas for improvement in its use in research regarding the lack of comparability of TCS scores across time. The lessons that have been learned should be used to adapt and expand the TCS overseas.

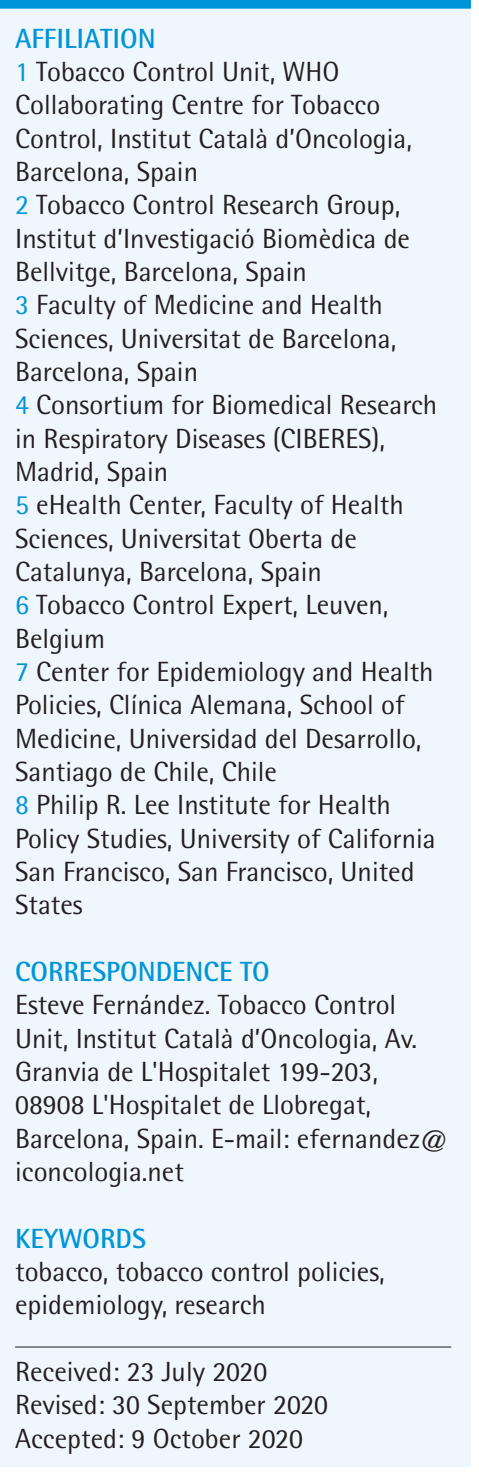

\section{INTRODUCTION}

Effective tobacco control policies help denormalize smoking, decrease smoking prevalence ${ }^{1}$, and reduce morbimortality attributable to tobacco ${ }^{2}$. Many efforts 
have been made globally to tackle the tobacco epidemic $^{3}$, stimulated by the enforcement of the Framework Convention on Tobacco Control. In the European Union (EU), the Tobacco Products Directive has driven the application of stringent tobacco control policies to reduce tobacco use and its negative consequences on health. However, the implementation and enforcement of tobacco control policies still vary greatly across Europe ${ }^{4}$.

Among the initiatives to monitor the implementation of tobacco control policies in Europe, Joossens and Raw $^{5}$ developed the Tobacco Control Scale (TCS) in 2006. The TCS score is determined by a questionnaire based on six cost-effective policy interventions that should be prioritized according to the World Bank. These measures include taxation, smoke-free policies, public spending in information campaigns, advertising bans, health warnings, and treatment. The score assigned to each of these components is weighted by its reported evidence-based effectiveness. Therefore, the score attributed to each country increases with the strength of tobacco control policies up to a maximum of 100 points, indicating full implementation ${ }^{5}$.

At its inception, the aim of the TCS was to monitor the progress in tobacco control in Europe at a national level by comparing the performance of countries by their ranking ${ }^{5}$ and to inform the agenda by highlighting the policy components for which progress is lacking, as well as the countries or regions most affected by such delays ${ }^{6}$. Since 2006, the TCS has been updated every three years (available at www. tobaccocontrolscale.org).

Evaluating the impact of tobacco control policies among the population has become an important research area; thus, the TCS has been used as a research tool to measure the implementation of tobacco control policies, though it was not designed for such purposes. However, little is known about the use of the TCS by the tobacco control research community and its advantages and disadvantages as a research tool. Therefore, our aim was to characterize the use of the TCS by researchers and its main limitations and strengths as a research tool in order to critically assess its use as a research instrument.

\section{METHODS}

\section{Data sources}

We performed an extensive literature search in the online databases PubMed and Web of Science to identify publications that have used the TCS score(s) as an independent or dependent variable from 27 March 2006, when the first TCS was published, until 1 December 2019. The search was conducted using 'tobacco control scale' as the keyword in all fields without any other restrictions to ensure a very sensitive search. The Ethics and Clinical Research Committee of the Hospital Universitari de Bellvitge approved this study (PR247/18).

\section{Study selection}

We identified 69 publications (32 duplicated in both databases). After removing duplicates, two researchers ( $\mathrm{AF}$ and $\mathrm{AB}$ ) screened the titles and abstracts, obtaining 32 studies. The inclusion criteria were quantitative research and inclusion of the TCS score(s) (as dependent or independent variable) in the analysis. We found 27 eligible publications (Figure 1). We completed our search by manually reviewing the reference lists of the selected papers and by conducting the same search in Google Scholar (www.scholar.google.com; with search terms in English). These additional searches provided five new publications that met the inclusion criteria and the full-texts were reviewed.

Therefore, we finally included 32 publications that used the TCS score(s) as a dependent or independent variable.

\section{Data extraction}

A detailed protocol and Microsoft Access ${ }^{\circledR}$ database were designed to extract and register the information from each publication. The evaluation protocol was developed by three researchers who are experts in tobacco control (AF, CM, and EF). The protocol describing the main objectives, information sources, search strategy and eligibility criteria, and the data collection was reviewed and approved by all researchers. All variables for which data were described in the publications' Methods sections were listed.

Two reviewers independently extracted the data according to the protocol ( $\mathrm{AF}$ and $\mathrm{AB}$ ). If any discrepancies emerged, the reviewers discussed the papers until agreement was reached and, when no consensus was met, divergences were solved by discussing them with a third reviewer (CM). The 
Figure 1. Flowchart of the selection process of publications for full-text review

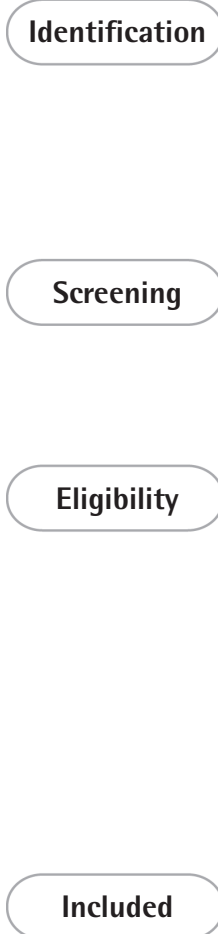

evaluation process was conducted in January 2020.

The extracted information included general characteristics, publication characteristics, research characteristics, and characteristics of the use of the TCS (Table 1).

\section{RESULTS}

The 32 publications were published between 2008 and 2019. More than two-thirds $(\mathrm{n}=23 ; 71.9 \%)$ were published by research groups from the Netherlands $(n=8)$, Spain $(n=9)$, and the United Kingdom $(n=6)$. Almost all $(\mathrm{n}=30 ; 93.8 \%)$ were original articles published in peer-reviewed journals, 12 of which were Open Access (37.5\%). In addition, almost all declared no conflicts of interest $(n=29 ; 90.6 \%)$ and were financially supported $(n=26 ; 81.3 \%)$ with public funds $(\mathrm{n}=19 ; 73.1 \%)$, both public and private funds $(n=5 ; 19.2 \%)$, or private funds $(n=2 ; 7.7 \%)$.

Most of the publications $(n=31)$ were observational studies; 16 used ecological data (50\%) with the country as the unit of analysis and 16 used multilevel data $(50 \%)$ with individual data from surveys as the first-level unit and TCS score by country as second-level aggregated information. Regarding the study design, 23 of the publications were crosssectional studies (78.6\%). Most of the articles $(n=24$; $75 \%$ ) (Table 2) included the TCS score(s) as an independent variable from primary reports, whereas 10 publications $(31.3 \%$ ) (Table 3 ) used the scores from secondary sources that calculated a new score based on the TCS methodology. Overall, $87.5 \%$ $(n=28)$ of the publications used the overall TCS score by country and $65.6 \%(n=21)$ used the individual policy component scores.

Twelve out of 21 articles (60\%) using individual TCS scores included all six policy components in the analysis. The most frequently used policy components were the individual score on bans in public places $(n=20 ; 95.2 \%)$ and advertising bans $(n=16 ; 76.2 \%)$. In contrast, the least used were data on public spending on information campaigns $(n=12 ; 57.1 \%)$. The publications included data from between 1 and 31 countries; only one publication used scores from all of the countries included in the TCS report, including $>30 \mathrm{EU}$ and non-EU countries ${ }^{7}$; however, $46.9 \%$ of publications included scores from all EU Member states except Croatia because it was first included in 2013. 
Table 1. Summary of the information extracted (variables and categories) from each publication

\begin{tabular}{|c|c|c|}
\hline & Variables & Categories \\
\hline \multirow[t]{3}{*}{ General } & $\begin{array}{l}\text { Author surname and initials, institutional affiliation, } \\
\text { and country of affiliation of the first author }\end{array}$ & \\
\hline & Funding & $\begin{array}{l}\text { Yes, no, or not declared; and if yes, private, public, or } \\
\text { both }\end{array}$ \\
\hline & Conflicts of interest & Yes, no, or not declared \\
\hline \multirow[t]{4}{*}{ Publication } & Type of publication & $\begin{array}{l}\text { Research paper, brief paper, review, letter to the editor, } \\
\text { editorial, comment, or other }\end{array}$ \\
\hline & Publication year & \\
\hline & Journal & \\
\hline & Open Access & Yes or no \\
\hline \multirow[t]{6}{*}{ Research } & Objective of the study & \\
\hline & Type of design & $\begin{array}{l}\text { Observational or experimental; cross-sectional or } \\
\text { longitudinal }\end{array}$ \\
\hline & Type of study data & $\begin{array}{l}\text { Individual, ecological, or multilevel, with individual } \\
\text { data from surveys as first level unit with TCS score by } \\
\text { country as second level of aggregated data }\end{array}$ \\
\hline & Main results & (literals) \\
\hline & $\begin{array}{l}\text { Limitations (specifically, those related to the use of } \\
\text { the TCS as a tool to monitor tobacco control policy } \\
\text { implementation) }\end{array}$ & (literals) \\
\hline & Main conclusions and their purpose & $\begin{array}{l}\text { For advocacy (when directly addressed to stakeholders } \\
\text { and policymakers), to undertake further research on } \\
\text { the topic, or both }\end{array}$ \\
\hline \multirow{6}{*}{$\begin{array}{l}\text { Use of the Tobacco } \\
\text { Control Scale (TCS) }\end{array}$} & Type of variable & Dependent, independent, or both \\
\hline & Year of the TCS report & \\
\hline & Source of the TCS score(s) & $\begin{array}{l}\text { Primary source, when publications included the TCS } \\
\text { score(s) from the original reports; or secondary source, } \\
\text { when publications included TCS data from other } \\
\text { publications in which case the alternative data source } \\
\text { was recorded }\end{array}$ \\
\hline & Total score & Yes or no \\
\hline & Individual components score(s) & Yes or no; and if yes, which components were included \\
\hline & Countries from the original TCS report(s) & $\begin{array}{l}\text { Yes or no; and if not, we recorded the number of } \\
\text { countries included }\end{array}$ \\
\hline
\end{tabular}

Half $(n=16)$ of the publications were directed towards policymakers with the aim of urging governments to implement more stringent tobacco control policies, 6 publications aimed to foster further research on this topic (18.8\%), and the conclusions of 10 papers $(31.3 \%)$ addressed both aims.

\section{Articles using TCS scores from primary reports}

Almost all of the studies that used the TCS reports as a primary source $(n=22)$ (Table 2$)$, were observational in nature $(n=21 ; 95.5 \%)$ and 19 were cross-sectional (86.4\%). According to the type of unit of analysis, half were ecological studies and half multilevel. These studies aimed to address the relationship between tobacco control policies and several outcomes, such as the prevalence of preterm births and low birthweight ${ }^{7}$, of hard-core and light smokers ${ }^{8}$, and of smoking in adolescents $^{9,10}$; smoking prevalence and quit ratios ${ }^{4,11}$; consumption of rolling tobacco, e-cigarettes, and readiness to quit in adults ${ }^{12}$; and risk of lung cancer ${ }^{13}$. Other indicators were smoking in private venues ${ }^{1,14}$, self-reported exposure to secondhand smoke (SHS) ${ }^{15-}$ ${ }^{17}$, and attitudes towards smoking and tobacco product restrictions ${ }^{18-21}$.

Other publications were focused on exploring the association between the price of tobacco products 
Table 2. Main characteristics of the studies that used the original TCS reports as primary data sources (N=22)

\begin{tabular}{|c|c|c|c|c|c|c|}
\hline $\begin{array}{l}\text { Reference, } \\
\text { location }\end{array}$ & Objective & Study design & $\begin{array}{l}\text { Use of TCS } \\
\text { (Type of variable, } \\
\text { original data, total } \\
\text { and components } \\
\text { score) }\end{array}$ & Main results & Limitations & Conclusions \\
\hline $\begin{array}{l}\text { Feliu et al. } \\
\text { 2019, Spain }\end{array}$ & $\begin{array}{l}\text { To empirically evaluate whether } \\
\text { the hardening hypothesis can be } \\
\text { confirmed at the population level } \\
\text { in the } 28 \text { EU member states, and to }\end{array}$ & $\begin{array}{l}\text { Observational, } \\
\text { multilevel, } \\
\text { time-trends }\end{array}$ & $\begin{array}{l}\text { Independent } \\
\text { variable, original } \\
\text { data, only total } \\
\text { score }\end{array}$ & $\begin{array}{l}\text { Hardening smoking is not increasing in EU member states } \\
\text { where smoking prevalence is decreasing. Odds of being a } \\
\text { hard-core smoker are higher among middle-aged men of } \\
\text { lower class and lower in countries with higher TCS scores }\end{array}$ & $\begin{array}{l}\text { No limitations reported about } \\
\text { the TCS as a variable }\end{array}$ & Advocacy \\
\hline
\end{tabular}

member states, and to analyze the determinants of hardcore and light smoking considering both individual and contextual country-level characteristics

González- $\quad$ To explore the association between

Marrón et al. ${ }^{13}$ the implementation of tobacco

2019, Spain control policies and the risk of lung cancer in the EU

Feliu et al. ${ }^{4} \quad$ To assess the midterm association of 2019, Spain tobacco control policies on smoking prevalence and quit ratios among 27 EU countries

Observational, Independent multilevel, variable, original cross-sectional data, only total score

Observational, Independent ecological, and variable, original cross-sectional data, total score and by components last decade

Significant inverse correlation between TCS 2010 and the proportion of former and ever smokers at high risk of lung cancer according to NELSON criteria

In EU27, countries with higher scores in the TCS has lower The TCS does not score the prevalence of smokers, higher quit ratios, and higher cor smoke-free policies and

Observational, Independent ecological, and variable, original cross-sectional data, total score and by components $\begin{array}{ll}\text { Diez-Izquierdo } & \text { To evaluate the correlation betwe } \\ \text { et al. } & \text { tobacco control policies and the }\end{array}$ 2018, Spain prevalence of preterm births and low birthweight in the European countries

Lidón-Moyano To describe the acceptability of some et al. ${ }^{18}$ 2018, Spain tobacco product regulations and to explore their relationship with tobacco control legislation levels in Europe

Observational, Dependent and ecological, and independent cross-sectional variable, original data, total score
The TCS score negatively correlated with the prevalence of preterm births for $<37$ weeks and $<32$ weeks and the prevalence of low birthweight $(<2500 \mathrm{~g})$ in European countries in 2010 and by components
Strong support for tobacco product regulations was observed. A positive relationship was found between TCS scores and support for tobacco product regulations at both the ecological and individual leve
The cross-sectional design of TCS limits the validity of the study to establish causation level of enforcement except the score may not fully reflect tobacco control policies implemented in subsequent years. The ranking of countries according to TCS scores has

been relatively consistent across different editions

Advocacy and research

\section{Advocacy} and research

No limitations reported about Advocacy the TCS as a variable

No limitations reported about Research the TCS as a variable 
Table 2. Continued

\begin{tabular}{|c|c|}
\hline $\begin{array}{l}\text { Reference, } \\
\text { location }\end{array}$ & Objective \\
\hline $\begin{array}{l}\text { Filippidis et } \\
\text { al. }^{22} 2017, \text { UK }\end{array}$ & $\begin{array}{l}\text { To examine associations between } \\
\text { median cigarette prices, price } \\
\text { differentials between cigarette } \\
\text { brands, and infant mortality }\end{array}$ \\
\hline $\begin{array}{l}\text { Filippidis et } \\
\text { al. }^{24} 2017, \text { UK }\end{array}$ & $\begin{array}{l}\text { To explore factors associated with } \\
\text { self-reported exposure of the EU } \\
\text { population to tobacco products and } \\
\text { electronic cigarette advertising }\end{array}$ \\
\hline
\end{tabular}
electronic cigarette advertising

\section{Kuipers et} al. ${ }^{23} 2017$, the

Netherlands

To estimate the impact of introducing sales restriction laws in European settings and to test whether the impact of the laws differed between adolescents of high and low socioeconomic position

Lidón-Moyano To analyze the correlation between et al. ${ }^{12}$ 2017, Spain the implementation of tobacco control policies and tobacco consumption, particularly rolling tobacco and e-cigarettes, and the intent to quit smoking in 27 countries of the EU

\section{Study design \\ Use of TCS \\ (Type of variable. \\ original data, total \\ and components \\ score)}

Observational, Independent

ecological, and variable, original

longitudinal

data, only by

components score

Larger differences between median and minimum

cigarette prices were associated with increased rates of

infant mortality. Median price increases during the study

period were associated with 9208 fewer infant deaths,

but a further 3195 infant deaths could have been avoided

if no price difference was observed between minimumpriced and median-priced cigarettes

Observational, Independent multilevel, and variable, origina

cross-sectional data, only by components score

$40.0 \%$ and $41.5 \%$ of respondents reported seeing any e-cigarette and tobacco product advertisement within the past year. Smokers, males, younger respondents,

those with financial difficulties, people who had tried e-cigarettes, and daily internet users were more likely to report it. Respondents in countries with more

comprehensive advertising bans were less likely to selfreport exposure to any tobacco, but not to e-cigarette advertisements

No decrease in smoking in countries that introduced sales restrictions for minors (2007-2011) compared

al, Indeper

multilevel, and variable, original

cross-sectional data, total score by components

Observational, Independent ecological, and variable, original cross-sectional data, total score and by components to countries that introduced these restrictions earlier (before 2007). Sales restrictions were associated with a stronger decrease in perceived ease of the obtainability of cigarettes. The results were similar for adolescents of high and low socio-economic position

An inverse correlation between TCS score and prevalence of smoking of conventional cigarettes and a positive correlation with the intent to quit smoking within

the past 12 months. The correlation between TCS and secondhand smoke (SHS) exposure at work was negative. Significant negative correlation between TCS score and the prevalence of having ever tried a waterpipe
No limitations reported about Advocacy

the TCS as a variable
Limitations

No limitations reported about the TCS as a variable

No limitations reported about Advocacy the TCS as a variable

The 2-year gap between the measure of the TCS and the Eurobarometer survey does not allow detection of the effect of measures adopted between 2010 and 2012 
Table 2. Continued

\begin{tabular}{|c|c|c|c|c|c|c|}
\hline $\begin{array}{l}\text { Reference, } \\
\text { location }\end{array}$ & Objective & Study design & $\begin{array}{l}\text { Use of TCS } \\
\text { (Type of variable, } \\
\text { original data, total } \\
\text { and components } \\
\text { score) }\end{array}$ & Main results & Limitations & Conclusions \\
\hline $\begin{array}{l}\text { Allen et al. }{ }^{35} \\
\text { 2016, UK }\end{array}$ & $\begin{array}{l}\text { To evaluate the potential } \\
\text { effectiveness of maximizing the } \\
\text { TCS score for the UK using a model } \\
\text { stratified by socio-economic } \\
\text { circumstances and to illustrate } \\
\text { health improvements associated with } \\
\text { reduced smoking prevalence }\end{array}$ & $\begin{array}{l}\text { Observational, } \\
\text { ecological, and } \\
\text { longitudinal }\end{array}$ & $\begin{array}{l}\text { Independent } \\
\text { variable, not } \\
\text { original data, only } \\
\text { total score }\end{array}$ & $\begin{array}{l}\text { Improvements in tobacco control policies towards } \\
\text { maximum TCS score could substantially reduce smoking } \\
\text { prevalence and reduce health-related inequalities }\end{array}$ & $\begin{array}{l}\text { Implementation was not } \\
\text { considered }\end{array}$ & Advocacy \\
\hline $\begin{array}{l}\text { Ferketich et al. }{ }^{1} \\
2016 \text {, USA }\end{array}$ & $\begin{array}{l}\text { To determine the relationship } \\
\text { between the TCS score and the } \\
\text { prevalence of in-home smoking bans } \\
\text { and beliefs on other tobacco control } \\
\text { policies }\end{array}$ & $\begin{array}{l}\text { Observational, } \\
\text { multilevel, and } \\
\text { cross-sectional }\end{array}$ & $\begin{array}{l}\text { Independent } \\
\text { variable, original } \\
\text { data, total score } \\
\text { and by components }\end{array}$ & $\begin{array}{l}\text { The TCS score was correlated with the prevalence of in- } \\
\text { home smoking bans. Four of the individual contributions } \\
\text { to the TCS scale (price, public campaigns, smoking bans } \\
\text { and health warnings) were significantly related to in- } \\
\text { home smoking bans }\end{array}$ & $\begin{array}{l}\text { No limitations involving the } \\
\text { use of TCS }\end{array}$ & $\begin{array}{l}\text { Advocacy } \\
\text { and research }\end{array}$ \\
\hline $\begin{array}{l}\text { Pförtner et al. }{ }^{10} \\
2016, \text { Germany }\end{array}$ & $\begin{array}{l}\text { To address to what extent different } \\
\text { measures of the TCS are associated } \\
\text { with smoking in adolescence in } 29 \\
\text { European countries and how the } \\
\text { association between tobacco control } \\
\text { policies and smoking varies by family } \\
\text { affluence }\end{array}$ & $\begin{array}{l}\text { Observational, } \\
\text { multilevel, and } \\
\text { cross-sectional }\end{array}$ & $\begin{array}{l}\text { Independent } \\
\text { variable, original } \\
\text { data, only by } \\
\text { components score }\end{array}$ & $\begin{array}{l}\text { Tobacco control policies did not strongly interact with } \\
\text { Family Affluence Scale (FAS) predicting adolescent } \\
\text { smoking. For boys, prevalence of smoking decreased with } \\
\text { higher tobacco price regardless of the socio-economic } \\
\text { background. For girls, no difference was found in smoking } \\
\text { prevalence by FAS }\end{array}$ & $\begin{array}{l}\text { a. The limited number of } \\
\text { observations at country } \\
\text { level and the low variance } \\
\text { of some tobacco policies } \\
\text { across countries may reduce } \\
\text { the robustness of parameter } \\
\text { estimates; b. Analyzed data } \\
\text { from the TCS has changed } \\
\text { since } 2006\end{array}$ & $\begin{array}{l}\text { Advocacy } \\
\text { and research }\end{array}$ \\
\hline $\begin{array}{l}\text { Filippidis et } \\
\text { al. }^{15} 2016 \text {, UK }\end{array}$ & $\begin{array}{l}\text { To explore whether exposure to } \\
\text { SHS among non-smokers in the } \\
\text { EU showed any association with } \\
\text { sociodemographic factors and/or the } \\
\text { extent of national tobacco control } \\
\text { policies }\end{array}$ & $\begin{array}{l}\text { Observational, } \\
\text { multilevel, and } \\
\text { cross-sectional }\end{array}$ & $\begin{array}{l}\text { Independent } \\
\text { variable, original } \\
\text { data, total score } \\
\text { and by components }\end{array}$ & $\begin{array}{l}29.0 \% \text { of non-smoking participants reported being } \\
\text { exposed to SHS in indoor areas. Males and individuals } \\
\text { with difficulties paying bills had significantly greater odds } \\
\text { of being exposed. For every unit increase of a country's } \\
\text { score on the Smoke-free Component of the TCS, the } \\
\text { probability of reporting exposure to SHS increased in } \\
\text { bars, restaurants, and workplaces }\end{array}$ & $\begin{array}{l}\text { No limitations reported about } \\
\text { the TCS as a variable }\end{array}$ & Advocacy \\
\hline
\end{tabular}


Table 2. Continued

\begin{tabular}{|c|c|c|c|c|c|c|}
\hline $\begin{array}{l}\text { Reference, } \\
\text { location }\end{array}$ & Objective & Study design & $\begin{array}{l}\text { Use of TCS } \\
\text { (Type of variable, } \\
\text { original data, total } \\
\text { and components } \\
\text { score) }\end{array}$ & Main results & Limitations & Conclusions \\
\hline $\begin{array}{l}\text { Martínez- } \\
\text { Sánchez et al. }{ }^{14} \\
\text { 2014, Spain }\end{array}$ & $\begin{array}{l}\text { To evaluate the correlation between } \\
\text { the implementation of tobacco } \\
\text { control policies and smoking } \\
\text { prevalence in private venues in the } \\
27 \text { countries of the EU }\end{array}$ & $\begin{array}{l}\text { Observational, } \\
\text { ecological, and } \\
\text { cross-sectional }\end{array}$ & $\begin{array}{l}\text { Independent } \\
\text { variable, original } \\
\text { data, total score } \\
\text { and by components }\end{array}$ & $\begin{array}{l}\text { No correlation was found between the implementation of } \\
\text { smoke-free legislation at work and in public places and } \\
\text { an increase in prevalence of smoking in private venues } \\
\text { in the EU. More developed smoke-free policies positively } \\
\text { correlated with a high prevalence of smoke-free houses }\end{array}$ & $\begin{array}{l}\text { No limitations reported about } \\
\text { the TCS as a variable }\end{array}$ & $\begin{array}{l}\text { Advocacy } \\
\text { and research }\end{array}$ \\
\hline $\begin{array}{l}\text { Rughinis et } \\
\text { al. }{ }^{9} 2014 \\
\text { Romania }\end{array}$ & $\begin{array}{l}\text { To investigate the relationship } \\
\text { between the number of cigarettes } \\
\text { smoked daily and habits and beliefs } \\
\text { concerning passive smoking }\end{array}$ & $\begin{array}{l}\text { Observational, } \\
\text { multilevel, and } \\
\text { cross-sectional }\end{array}$ & $\begin{array}{l}\text { Independent } \\
\text { variable, original } \\
\text { data, only total } \\
\text { score }\end{array}$ & $\begin{array}{l}\text { Light smokers are less likely to have houses and cars } \\
\text { in which smoking is allowed, to have visited drinking } \\
\text { or eating establishments that allow smoking, and to } \\
\text { be systematically exposed to tobacco smoke in the } \\
\text { workplace }\end{array}$ & $\begin{array}{l}\text { No limitations reported about } \\
\text { the TCS as a variable }\end{array}$ & Advocacy \\
\hline $\begin{array}{l}\text { Kovess et al. }{ }^{16} \\
\text { 2013, France }\end{array}$ & $\begin{array}{l}\text { To ascertain patterns of parental } \\
\text { smoking in the vicinity of children in } \\
\text { Eastern and Western Europe and their } \\
\text { relation to TCS scores }\end{array}$ & $\begin{array}{l}\text { Observational, } \\
\text { multilevel, and } \\
\text { cross-sectional }\end{array}$ & $\begin{array}{l}\text { Independent } \\
\text { variable, original } \\
\text { data, only total } \\
\text { score }\end{array}$ & $\begin{array}{l}\text { Eastern European parents were about twice as likely to } \\
\text { smoke near their children as those in Western Europe. } \\
\text { Current maternal smoking prevalence was similar. A } \\
\text { strong relationship was observed between parental } \\
\text { education, tobacco control policies, and smoking near the } \\
\text { child }\end{array}$ & $\begin{array}{l}\text { No limitations reported about } \\
\text { the TCS as a variable }\end{array}$ & Advocacy \\
\hline $\begin{array}{l}\text { Willemsen et } \\
\text { al. }^{20} \\
2012 \text {, the } \\
\text { Netherlands }\end{array}$ & $\begin{array}{l}\text { To examine how a country's level } \\
\text { of tobacco control is associated } \\
\text { with markers of denormalization of } \\
\text { smoking, smoking prevalence, and } \\
\text { societal support for tobacco control }\end{array}$ & $\begin{array}{l}\text { Observational, } \\
\text { ecological, and } \\
\text { cross-sectional }\end{array}$ & $\begin{array}{l}\text { Dependent and } \\
\text { independent } \\
\text { variable, original } \\
\text { data, only total } \\
\text { score }\end{array}$ & $\begin{array}{l}\text { Smokers in EU countries with higher TCS scores are } \\
\text { more concerned about the effect of smoking. Support } \\
\text { for tobacco policies is higher in countries with more } \\
\text { concerned smokers }\end{array}$ & $\begin{array}{l}\text { No limitations reported about } \\
\text { the TCS as a variable }\end{array}$ & $\begin{array}{l}\text { Advocacy } \\
\text { and research }\end{array}$ \\
\hline $\begin{array}{l}\text { Bogdanovica } \\
\text { et al. }^{25} \\
2011 \text {, UK }\end{array}$ & $\begin{array}{l}\text { To test the hypothesis that smoking } \\
\text { prevalence is higher in countries } \\
\text { with high levels of public sector } \\
\text { corruption and explore the ecological } \\
\text { association between smoking } \\
\text { prevalence and a range of other } \\
\text { national characteristics in current EU } \\
\text { Member States }\end{array}$ & $\begin{array}{l}\text { Observational, } \\
\text { ecological, and } \\
\text { cross-sectional }\end{array}$ & $\begin{array}{l}\text { Dependent variable, } \\
\text { original data, } \\
\text { total score and by } \\
\text { components }\end{array}$ & $\begin{array}{l}\text { Smoking prevalence was significantly higher in countries } \\
\text { with higher scores for corruption, material deprivation, } \\
\text { and gender inequality, and lower in countries with higher } \\
\text { gross domestic product per capita, social spending, life } \\
\text { satisfaction, and human development scores }\end{array}$ & $\begin{array}{l}\text { No limitations reported about } \\
\text { the TCS as a variable }\end{array}$ & Advocacy \\
\hline
\end{tabular}


Table 2. Continued

\begin{tabular}{|c|c|}
\hline $\begin{array}{l}\text { Reference, } \\
\text { location }\end{array}$ & Objective \\
\hline $\begin{array}{l}\text { Martínez- } \\
\text { Sánchez et al. }{ }^{21} \\
\text { 2010, Spain }\end{array}$ & $\begin{array}{l}\text { To describe the correlation between } \\
\text { the TCS and smoking prevalence, } \\
\text { self-reported exposure to SHS, } \\
\text { and attitudes towards smoking } \\
\text { restrictions in the } 27 \text { countries of } \\
\text { the EU }\end{array}$ \\
\hline
\end{tabular}

Tual et al. ${ }^{17} \quad$ To explore the relationship between

2010, France SHS exposure and the strength of national-level tobacco control policies

Hublet et al. ${ }^{9} \quad$ To investigate smoking policies in 29 2009, Belgium European countries in relation to the national smoking prevalence among young people

Schaap et To examine the extent to which

al. ${ }^{11} 2008$, the tobacco control policies correlate

Netherlands

\section{Study design \\ Use of TC \\ (Type of variable. \\ original data, total \\ and components

$$
\text { score }
$$

Observational, Independent

ecological, and variable, original

A direct non-significant association was found between

TCS scores and the prevalence of smoke-free houses,

cross-sectional data, total score

and a non-significant inverse correlation with allowing

and by components smoking in certain rooms

Observational, Dependent variable, The Carbone monoxide concentration decreased with the multilevel, and original, data only cross-sectional total score

strength of tobacco control policies, as scored by the TCS in a large non-smoker European population

Observational, Independent

multilevel, and variable, original

cross-sectional data, total score and by components

Observational, Independent

ecological, and variable, original

cross-sectional data, total score

and by components
$3.8 \%$ variance in regular smoking in boys and 3.5\% in girls can be attributed to country structure or country of residence. In boys, this variance is associated with

High-educated smokers were more likely to quit smoking in all age-sex groups. TCS score was positively associated with quit ratios in all age-sex groups, with no consisten differences between high and low education country-level tobacco control
No limitations reported about Advocacy

the TCS as a variable

No limitations reported about Advocacy the TCS as a variable and research

No limitations reported about Advocacy the TCS as a variable

The information described by the TCS score is about policies in 2005 and recently implemented policies are not incorporated; therefore, the impact of such policies may be underestimated when using the current version of the TCS 
Table 3. Main characteristics of the studies that used the TCS from a secondary source and estimated the scores of the countries using TCS methodology (N=10)

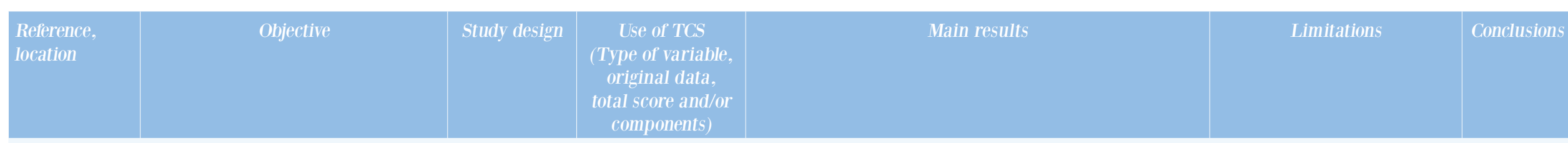

\section{So et al. ${ }^{26} \quad$ To describe changes in smoking}

2019, UK

prevalence over time within EU

member states from 2009-2017;

to describe how within-country

and between-country variations

in the implementation of tobacco

control policies are associated with

current smoking in individuals; and

to describe how these variations

affect individuals of different socio-

economic positions.

Serrano- $\quad$ To evaluate the impact of tobacco

Alarcón et al. ${ }^{27}$ control policies on smoking among

2019, Portugal older adults in Europe from 20042013

Bosdriesz et To assess whether tobacco control al. ${ }^{31}$

2016, the

Netherlands policy was associated with socioeconomic inequalities in smoking across the EU in the period 20062012

Bosdriesz et To assess whether developments al. ${ }^{32}$

2015, the

Netherlands

Netherlands were associated with

smoking cessation and smoking

intensity.

\section{Observational, Independent \\ multilevel, and variable, not \\ longitudinal original data, only \\ total score}

A general trend of decreasing smoking prevalence over

No limitations reported about Research the last decade was found in the EU. There was significant the TCS as a variable

the country level and country-year level

ndicating that countries differed significantly in their

smoking prevalence trajectory. Strong tobacco control policies were significantly associated with lower odds of being a current smoker, with a greater effect in upper

class occupations

Observational, Independent multilevel, and variable, not longitudinal original data, total score and by components

Observational, Independent multilevel, and variable, not longitudinal original data, total score and by components

Observational, Independent multilevel, and variable, not longitudinal original data, only by components score
A 10-point increase in the TCS score was associated with a drop in the probability of smoking by 1.1 percentage points (not significant). Pricing and smoke-free policies were significantly associated with smoking

An association was found between tobacco control policies and smoking cessation among higher educated smokers. In middle- and high-educated smokers, policies were also associated with a decrease in smoking intensity

Progress in tobacco control policy in the Netherlands was significantly associated with an increase in the quit ratios (2001-2011) but were not significantly associated with smoking intensity among smokers. The strength of the associations was similar for low- and high-education groups
No limitations involving the

use of TCS

Research

No limitations involving the

Advocacy use of TCS

No limitations reported about the TCS as a variable

Advocacy and research 
Table 3. Continued

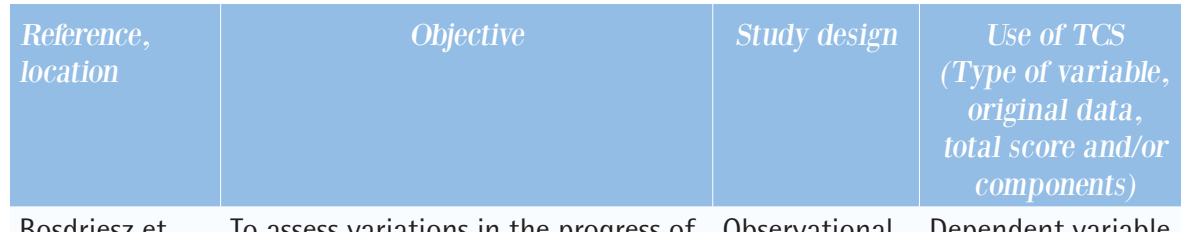

Bosdriesz et

al. ${ }^{30}$

2015, the

Netherlands

To assess variations in the progress of tobacco control policy development

Observationa cological, and in Europe and to identify whether the
variations can be decomposed into specific patterns or components

Klumbiene To evaluate the association between et al. ${ }^{29} 2015$, tobacco control policies and trends

Lithuania in smoking cessation in Lithuania in

Kuipers et al. ${ }^{28} \quad$ To examine the association 2015, the between tobacco control policies

Netherlands and adolescent smoking, and to

Bosdriesz et To provide insight into the role of al. ${ }^{6} \quad$ political factors in the development 2015, the of tobacco control policy over time

Netherlands

Movsisyan et al. ${ }^{33} 2014$, Armenia 1994-2010 investigate the differences in this association between adolescents of high and low socio-economic status (SES)

Observational, Independent ecological, and variable, not longitudinal original data, total score and by components

Observational, Independent multilevel, and variable, not cross-sectional original data, only total score

Great progress in the development of tobacco control policy has been achieved in Lithuania. This progress was associated with an increase in smoking cessation. This association was stronger among younger than older people

Adolescent smoking prevalence rates were higher among low-SES respondents than their high-SES peers. Stronge national-level tobacco control policies were associated with lower odds of daily smoking

Observational, Dependent variable ecological, and not original, total longitudinal score and by components

To measure the 5-year progress in the implementation of FCTC in Armenia cross-sectional score and by

components
An association was found between left-wing government and TCS over the period 1996-2003, but not over the whole studied period (1996-2010). The association between government effectiveness and TCS was significant and negative over the whole period, but positive between 2001 and 2005

, The estimated TCS score for Armenia for smoke-free public places, advertising ban, health warnings, and

treatment are below the European average (2005-2007)

However, the score estimate for price and public spending are above average
Limitations

Conclusions

in the current study contains five domains of tobacco control, not all of which may be as likely to affect adolescent smoking

The TCS contains little information on their enforcement in practice

a. Potential measurement error; b. inadequate accuracy nd comparability of data; $c$. the estimates could have been affected by exchange rate fluctuations Advocacy and research

Advocacy

and research

Advocacy

Continued 
Table 3. Continued

\begin{tabular}{|c|c|c|c|c|c|c|}
\hline $\begin{array}{l}\text { Reference, } \\
\text { location }\end{array}$ & Objective & Study design & $\begin{array}{c}\text { Use of TCS } \\
\text { (Type of variable, } \\
\text { original data, } \\
\text { total score and/or } \\
\text { components) }\end{array}$ & Main results & Limitations & Conclusions \\
\hline $\begin{array}{l}\text { Heydari et al. }{ }^{34} \\
\text { 2012, Iran }\end{array}$ & $\begin{array}{l}\text { To obtain an overview of tobacco } \\
\text { control strategies in the Eastern } \\
\text { Mediterranean region }\end{array}$ & $\begin{array}{l}\text { Observational, } \\
\text { ecological, and } \\
\text { cross-sectional }\end{array}$ & $\begin{array}{l}\text { Dependent variable, } \\
\text { not original, total } \\
\text { score and by } \\
\text { components }\end{array}$ & $\begin{array}{l}\text { Afghanistan scored highest for tobacco pricing. } \\
\text { Oman scored higher than others for regulations and } \\
\text { enforcement of bans on smoking in public places. The } \\
\text { Islamic Republic of Iran had the top score on budgeting } \\
\text { for tobacco control activities, in prohibition and } \\
\text { enforcement of tobacco advertising, and placement } \\
\text { of health warnings on cigarette packets. Syrian Arab } \\
\text { Republic, Tunisia, and Kuwait had the best provision } \\
\text { of smoking cessation services, whereas Pakistan, Saudi } \\
\text { Arabia, Somalia, and Yemen scored zero }\end{array}$ & $\begin{array}{l}\text { As the data were extracted } \\
\text { from sources such as MPOWER } \\
\text { measures and the Tobacco } \\
\text { Atlas, they may not cover all } \\
\text { important variables and the } \\
\text { results may not be conclusive }\end{array}$ & Research \\
\hline
\end{tabular}


and infant mortality ${ }^{22}$, the effects of sales restriction laws on adolescents ${ }^{23}$, and the factors associated with exposure to tobacco and e-cigarette advertising ${ }^{24}$. One study assessed the association between smoking prevalence and public sector corruption and other national characteristics ${ }^{25}$. The main characteristics and results of each article are given in Table 2.

Articles using TCS methodology to compute new scores As shown in Table 3, ten studies calculated new scores to measure tobacco control policies at a country level in a particular year using the TCS rationale and methodology instead of the original TCS. Most of these studies used data from European countries with a longitudinal design aimed at assessing the association between tobacco control policies and smoking ${ }^{6,26,27}$ and socio-economic inequalities outcomes in adolescents ${ }^{28}$ or adults over time ${ }^{29-31}$, or to examine political factors that drive tobacco control policy development ${ }^{32}$. According to the type of data, these publications were half ecological and half multilevel studies.

Two publications computed scores for nonEuropean countries to monitor their tobacco control policy implementation by using the same rationale and methodology. These publications were aimed at measuring the progress after implementation of the WHO-FCTC in Armenia ${ }^{33}$ and providing an overview and comparing the tobacco control progress in Eastern Mediterranean countries ${ }^{34}$. The main characteristics and results of each study are shown in Table 3.

Main limitations of the TCS mentioned by the studies Only $11(34.4 \%)$ of all publications included comments on the limitations of using the TCS score as a tool to assess tobacco control policies. The main limitations reported by the studies were that they failed to express the degree to which legislative policies are enforced ${ }^{6,32,35}$, except for the smoke-free policies $^{4}$. Another limitation is that the countries' rankings have only slightly changed over the years (i.e. the UK has remained in the top position from 2007 to 2016$)^{4}$. This low variance across countries may reduce the robustness of the results of the studies ${ }^{10}$. Moreover, some studies reported that the information described by the TCS score(s) does not incorporate the most recent national legislation on tobacco control due to its cross-sectional design ${ }^{13}$, potentially underestimating the impact of such policies when using the TCS ${ }^{11}$.

Finally, among the studies not using data from the original TCS reports, the main limitations were that some policy areas could not be quantified accurately and that some of the policy components assessed by the TCS could not be included ${ }^{34}$ because of potential error in the measurement of their estimates, and inadequate accuracy and comparability of the data ${ }^{33}$.

\section{DISCUSSION}

Our results reveal that the TCS has been used mostly in observational, cross-sectional studies with either ecological (country as the unit of analysis) or multilevel data (individual data from surveys as the first-level unit and TCS score by country as secondlevel aggregated information). The TCS score has been mainly used as an independent variable to explain the potential variation in outcomes (i.e. tobacco product use, exposure to SHS, attitudes towards legislation, etc.), and mostly employed in European countries, as these countries were the target of the TCS when it was created.

\section{Interpretation of the results}

This is the first attempt to assess all of the available publications that have used the TCS as a means to measure tobacco control policy implementation since it was developed in 2006. In addition, this is the first study to map out the characteristics of the use of the TCS in scientific research, to understand how this tool has been applied despite its original design as a means to advocate for comprehensive tobacco control policies. Therefore, our findings suggest that the TCS has commonly been used as an indicator of the state of tobacco control policies in Europe.

Almost all of the studies assessed tobacco control policies through the total TCS score, and most have used the policy components scores from the primary published reports. The policy components most commonly studied were public smoking bans and tobacco product advertising bans, possibly because they are two of the measures that have been most frequently regulated in Europe since the WHO-FCTC came into force in $2005^{36}$.

Another important issue to address is the crosssectional and temporal comparability of the TCS because most of the studies make comparisons across countries and/or over time. Notably, Joossens and 
$\mathrm{Raw}^{5}$ designed the scale to compare tobacco control policies across countries at a particular time point. Thus, the reference values for scores are sustained across each report. However, these scores are not comparable across years because these standards have changed over time (i.e. the weighted average price for cigarettes was $€ 8.5$ in 2013 and $€ 10$ in 2016, considering the EU average Purchasing Power Standard $)^{37,38}$; on the other hand, the scale methodology and scoring system changed between 2007 and $2010^{39}$. Consequently, longitudinal studies to ensure temporal comparability between and within countries require adjusting scores to the highest standards by an escalation process and re-calculating scores from the 2005 and 2007 reports using the newest scoring system and methodology.

Importantly, most of the studies with a longitudinal design conducted in Europe have adapted the scale rationale and methods to estimate the level of implementation of tobacco control policies to ensure the temporal comparability and include data about years for which the TCS had not been published ${ }^{26,27,29,31,32}$. Few non-European countries have adapted the scale as a proxy to monitor the status of tobacco control policies in non-European countries ${ }^{33,34}$. Unfortunately, most of these studies did not clearly explain how they adapted the TCS to estimate new score(s) for each policy component. Therefore, new studies should provide a full description of their adaptation process and the potential limitations and strengths not only to ensure its replication, but also to further develop strategies to adapt the TCS to other contexts overseas.

These results highlight that the TCS, regardless of its limitations, has been applied as an objective indicator to measure the strength of the implementation of tobacco control policies at the country level. Other studies have used a total score obtained from summing the scores (from 1 to 5 ) assigned to each MPOWER policy dimension in the WHO's Reports on the Global Tobacco Epidemic ${ }^{40,41}$. MPOWER's composite score has some clear advantages over the TCS total score because it is available for all countries, not only European countries, and is comparable over time. However, this proxy also has some disadvantages for research purposes. First, it assigns the same weight to each of the six individual MPOWER scores without taking into consideration that some MPOWER measures have been proven to be more effective than other measures (i.e. taxation). Second, MPOWER's composite score has a narrower score range than the TCS score (6-29 vs 0-100, respectively), which limits variation across countries and may make it difficult to address variability between countries. Finally, unlike the MPOWER composite score, the TCS score is not affected by the government's political agenda, as the TCS is built on information from objective databases (i.e. Eurostat) and the Civil Society.

More than $65 \%$ of the reviewed publications did not report any limitation of the TCS as a proxy for measuring tobacco control policies. Nonetheless, Joossens and Raw ${ }^{5}$ already reported some of its major limitations, including difficulties in assessing enforcement versus implementation and its critical dependence on tobacco control experts' judgement when scoring ${ }^{5}$. Therefore, such underreporting of limitations makes it difficult to fully describe the limitations that researchers encounter, which is indispensable to moving forward in the field. Among the articles reporting limitations, most of them highlighted the fact that the TCS score(s) did not measure the enforcement of policies except smokefree policies. In this sense, no previous studies have examined the disparity between the implementation and enforcement of tobacco control policies; however, the TCS being predictive of so many outcomes suggests that the implementation of these policies is a good proxy of enforcement. In addition, some studies have questioned the ability of the TCS to incorporate new policies, such as smoke-free outdoor policies, indicating that the authors of the TCS should discuss how to incorporate these new tobacco control policies and which weight they should have in the scale.

Moreover, our study shows that the TCS has been commonly used in Europe over the last decade, but three research groups from Spain, the Netherlands, and the UK account for more than half of the publications using the TCS for research purposes. This suggests that these groups have led and consolidated the use of this monitoring tool in the tobacco control research field. This is supported by the fact that the publications conducted by these three research groups have received a higher number of citations, including a paper ${ }^{13}$ with 54 citations and another paper ${ }^{23}$ with 103 citations (in Web of Science) up to December 2019.

More than half of all publications directed their 
conclusions towards advocacy for improving tobacco control policies. Therefore, most authors find the TCS useful for linking data to policy action, even though the TCS has been commonly used for research purposes. Therefore, the TCS has not lost its intended original purpose for advocacy, as it was developed to detect areas of improvement within each country and to establish comparisons among countries through a ranking, in order to motivate governments to strengthen their weakest polices ${ }^{5}$.

Our results indicate that, despite its potential limitations and lack of a formal validity assessment, the TCS is a good proxy of the strength of tobacco control policies implementation, or at least the best approximation developed so far. However, the TCS has been used at face-value. No attempts have been made to formally validate the scale. Construct validity of the TCS is a complex issue given the composite structure of the TCS itself, though some dimensions are based on objective data (i.e. price and SHS exposure) from population-based surveys and reports of the European Commission; others are based on the answers of one or two informants to an ad hoc questionnaire (i.e. cessation budget at national level) ${ }^{5}$.

\section{Limitations and strengths}

Publication bias is a potential source of error when the units of the investigation are published papers ${ }^{42}$. We searched the available literature in PubMed, the main biomedical database, as well as Web of Science and Google Scholar, and checked all references to identify other articles not published in academic journals. However, the possibility that unpublished manuscripts or other documents addressing the topic of interest may have been missed cannot be ruled out, but it was an a priori decision made by the experienced research team that was composed of tobacco control and policy experts, including the author of the TCS. Under these circumstances, selection (publication) bias seems unlikely to have affected the study.

Other potential limitations of our study are linked to the fact that a high number of the publications analyzed here did not include any comment about the limitations and strengths of using TCS scores as a variable to monitor tobacco control policy implementation in research. This missed reporting has hindered the identification of the main limitations and strengths of this tool for different types of study designs, outcomes, or statistical analysis; therefore, our study may have some missing information.

However, our study is the first to assess all published articles using the TCS as an indicator of tobacco control policy implementation and to characterize its use in tobacco control research, giving a full and comprehensive overview of how and for which purposes the TCS has been employed in previous studies. This study also presents information on how to best use the TCS as described by the authors in the Limitations sections of the publications. Thus, our study presents the lessons learned from previous research, creating an opportunity for researchers to plan to use the TCS to improve the quality of future studies.

\section{CONCLUSIONS}

This study shows that the TCS has been commonly used in observational, mostly ecological, studies to assess variations in a concrete outcome according to the policies instituted in Europe as a proxy of tobacco control implementation. In addition, the TCS has been employed to detect changes in individual and population outcomes (i.e. smoking prevalence or cessation) and establish conclusions about how policies have an effect in specific populations.

Our recommendations to researchers and policymakers planning to use the TCS in their future research are as follows. First, the TCS scoring methodology needs to be fully understood, as comparability is not ensured among countries across years. Second, researchers should consider a certain time gap between measuring the TCS score and the outcomes, as the TCS may not include the most recently adopted policies and policies need time to have an effect. Third, knowing the limitations of the TCS in measuring implementation (vs enforcement) of tobacco control policies is important. Fourth, researchers need to take into account the low variance of some tobacco control policies across countries, which may also reduce the robustness of the estimates.

A logical next step for future applications of the TCS in research would be to study the impact of tobacco control policy enforcement in terms of several indicators, such as prevalence, SHS, and tobacco sales, and to assess the impact of these policies at the population level. To achieve this goal, more extensive cross-country population-based surveys are needed to include new enforcement measures in future editions 
of the TCS (i.e. about compliance with smoke-free bans in public places differently than workplaces and hospitality venues, or about advertising, promotion, and sponsorship bans).

Finally, to gain a broader perspective of tobacco control as a public health need and build a stronger tool for tobacco research, we suggest adapting and extending the TCS to other countries of the WHO European Region, and to the reality of other regions of the globe, such as Latin America or Asia, incorporating local and cultural characteristics of these regions while preserving the comparability among countries worldwide.

\section{REFERENCES}

1. Ferketich AK, Lugo A, La Vecchia C, et al. Relation between national-level tobacco control policies and individual-level voluntary home smoking bans in Europe. Tob Control. 2014;25(1):60-65. doi:10.1136/tobaccocontrol-2014-051819

2. Bertollini R, Ribeiro S, Mauer-Stender K, Galea G. Tobacco control in Europe: a policy review. Eur Respir Rev. 2016;25(140):151-157. doi:10.1183/16000617.0021-2016

3. International Agency for Research on Cancer. Evaluating the effectiveness of smoke-free policies. IARC Handbook of Cancer Prevention: Tobacco Control. Vol 13. Lyon: International Agency for Research on Cancer; 2009.

4. Feliu A, Filippidis FT, Joossens L, et al. Impact of tobacco control policies on smoking prevalence and quit ratios in 27 European Union countries from 2006 to 2014. Tob Control. 2019;28:101-109. doi:10.1136/tobaccocontrol-2017-054119

5. Joossens L, Raw M. The Tobacco Control Scale: a new scale to measure country activity. Tob Control. 2006;15:247-253. doi:10.1136/tc.2005.015347

6. Bosdriesz JR, Willemsen MC, Stronks K, Kunst A. Patterns of tobacco control policy progress in 21 European countries. Tob Regul Sci. 2015;1:254-264. doi:10.18001/ TRS.1.3.7

7. Díez-Izquierdo A, Balaguer A, Lidón-Moyano C, et al. Correlation between tobacco control policies and preterm births and low birth weight in Europe. Environ Res. 2018;160:547-553. doi:10.1016/j.envres.2017.10.033

8. Feliu A, Fernandez E, Martinez C, Filippidis F. Are smokers 'hardening' or rather 'softening'? An ecological and multilevel analysis across 28 European Union countries. Eur Respir J. 2019;54(3):1900596. doi:10.1183/13993003.00596-2019

9. Hublet A, Schmid H, Clays E, et al. Association between tobacco control policies and smoking behaviour among adolescents in 29 European countries. Addiction. 2009;104:1918-1926. doi:10.1111/j.1360-0443.2009.02686.x

10. Pförtner TK, Hublet A, Warrer C, et al. Socioeconomic inequalities in the impact of tobacco control policies on adolescent smoking. A multilevel study in 29
European countries. Addict Behav. 2016;53:58-66. doi:10.1016/j.addbeh.2015.09.016

11. Schaap MM, Kunst AE, Leinsalu M, et al. Effect of nationwide tobacco control policies on smoking cessation in high and low educated groups in 18 European countries. Tob Control. 2008;17(4):248-255. doi:10.1136/tc.2007.024265

12. Lidón-Moyano C, Martín-Sánchez JC, Saliba P, Graffelman J, Martínez-Sánchez J. Correlation between tobacco control policies, consumption of rolled tobacco and e-cigarettes, and intention to quit conventional tobacco, in Europe. Tob Control. 2017;26(2):149-152. doi:10.1136/tobaccocontrol-2015-052482

13. González-Marrón A, Martín-Sánchez JC, Miró Q, et al. Relation between tobacco control policies and population at high risk of lung cancer in the European Union. Environ Res. 2019;179:108594. doi:10.1016/j.envres.2019.108594

14. Martínez-Sánchez JM, Blanch C, Fu M, Gallus S, La Vecchia C, Fernández E. Do smoke-free policies in work and public places increase smoking in private venues? Tob Control. 2014;23(3):204-207. doi:10.1136/tobaccocontrol-2012-050877

15. Filippidis FT, Agaku IT, Girvalaki C, et al. Relationship of secondhand smoke exposure with sociodemographic factors and smoke-free legislation in the European Union. Eur J Public Health. 2016;26:344-349. doi:10.1093/eurpub/ckv204

16. Kovess V, Pilowsky DJ, Boyd A, et al. Parental smoking in the vicinity of children and tobacco control policies in the European Region. PLoS One. 2013;8:e56783. doi:10.1371/journal.pone.0056783

17. Tual S, Piau JP, Jarvis MJ, Dautzenberg B, Annesi-Maesano I. Impact of tobacco control policies on exhaled carbon monoxide in non-smokers. J Epidemiol Community Heal. 2010;64:554-556. doi:10.1136/jech.2008.086256

18. Lidón-Moyano C, Sampedro-Vida M, Matilla-Santander N, et al. Attitudes towards tobacco product regulations and their relationship with the tobacco control policies. Prev Med. 2018;111:67-72. doi:10.1016/j.ypmed.2018.02.019

19. Rughinis C, Rughiniş R. Influence of daily smoking frequency on passive smoking behaviors and beliefs. Revista de Cercetare si Interventie Sociala. 2014;44:116131.

20. Willemsen MC, Kiselinova M, Nagelhout GE, Joossens L, Knibbe R. Concern about passive smoking and tobacco control policies in European countries: An ecological study. BMC Public Health. 2012;12:876. doi:10.1186/1471-2458-12-876

21. Martínez-Sánchez JM, Fernández E, Fu M, et al. Smoking behaviour, involuntary smoking, attitudes towards smoke-free legislations, and tobacco control activities in the European Union. PLoS One. 2010;5(11):e13881. doi:10.1371/journal.pone.0013881

22. Filippidis FT, Laverty AA, Hone T, Been J, Millett C. Association of cigarette price differentials with infant mortality in 23 European Union countries. JAMA Pediatr. 
2017;171:1100-1106. doi:10.1001/jamapediatrics.2017.2536

23. Kuipers MAG, Brandhof SD, Monshouwer K, Stronks K, Kunst A. Impact of laws restricting the sale of tobacco to minors on adolescent smoking and perceived obtainability of cigarettes: an intervention-control pre-post study of 19 European Union countries. Addiction. 2017;112(2):320329. doi:10.1111/add.13605

24. Filippidis FT, Laverty AA, Fernandez E, Mons U, Tigova O, Vardavas C. Correlates of self-reported exposure to advertising of tobacco products and electronic cigarettes across 28 European Union member states. Tob Control. 2017;26:e130-e133. doi:10.1136/tobaccocontrol-2016-053479

25. Bogdanovica I, McNeill A, Murray R, Britton J. What Factors influence smoking prevalence and smoke free policy enactment across the European union Member States. PLoS One. 2011;6(8):e23889. doi:10.1371/journal.pone.0023889

26. So VHT, Best C, Currie D, Haw S. Association between tobacco control policies and current smoking across different occupational groups in the EU between 2009 and 2017. J Epidemiol Community Health. 2019;73:759767. doi:10.1136/jech-2018-211935

27. Serrano-Alarcón M, Kunst AE, Bosdriesz JR, Perelman J. Tobacco control policies and smoking among older adults: a longitudinal analysis of 10 European countries. Addiction. 2019;114:1076-1085. doi:10.1111/add.14577

28. Kuipers MAG, Monshouwer K, Van Laar M, Kunst A. Tobacco Control and Socioeconomic Inequalities in Adolescent Smoking in Europe. Am J Prev Med. 2015;49:e64-e72. doi:10.1016/j.amepre.2015.04.032

29. Klumbiene J, Sakyte E, Petkeviciene J, Prattala R, Kunst A. The effect of tobacco control policy on smoking cessation in relation to gender, age and education in Lithuania, 1994-2010. BMC Public Health. 2015;181:110. doi:10.1186/s12889-015-1525-8

30. Bosdriesz JR, Nagelhout GE, Stronks K, Willemsen M, Kunst A. The Association Between Tobacco Control Policy and Educational Inequalities in Smoking Cessation in the Netherlands from 1988 Through 2011. Nicotine Tob Res. 2015;17:1369-1376. doi:10.1093/ntr/ntv004

31. Bosdriesz JR, Willemsen MC, Stronks K, Kunst A. Tobacco control policy and socio-economic inequalities in smoking in 27 European countries. Drug Alcohol Depend. 2016;165:79-186. doi:10.1016/j.drugalcdep.2016.05.020

32. Bosdriesz JR, Willemsen MC, Stronks K, Kunst A. Tobacco control policy development in the European Union: do political factors matter? Eur J Public Health. 2015;25:190-194. doi:10.1093/eurpub/cku197

33. Movsisyan NK, Connolly GN. Measuring Armenia's progress on the Tobacco Control Scale: an evaluation of tobacco control in an economy in transition, 2005-2009. BMJ Open. 2014;4:e004410. doi:10.1136/bmjopen-2013-004410

34. Heydari G, Talischi F, Masjedi MR, Alguomani H, Joossens L, Ghafari M. Comparison of tobacco control policies in the Eastern Mediterranean countries based on tobacco control scale scores. East Mediterr Heal J. 2012;18:803-

\section{0. doi:10.26719/2012.18.8.803}

35. Allen K, Kypridemos C, Hyseni L, et al. The effects of maximising the UK's tobacco control score on inequalities in smoking prevalence and premature coronary heart disease mortality : a modelling study. BMC Public Health. 2016;16:1-10. doi:10.1186/s12889-016-2962-8

36. World Health Organization. WHO Report on the Global Tobacco Epidemic, 2017: Monitoring tobacco use and prevention policies. Geneva: World Health Organization; 2017.

37. Joossens L, Raw M. The Tobacco Control Scale 2013 in Europe. Brussels: Association of European Cancer Leagues; 2014. https://www.tobaccocontrolscale.org/ TCS2013.pdf. Accessed July 23, 2020.

38. Joossens L, Raw M. The Tobacco Control Scale 2016 in Europe. Brussels: Association of European Cancer Leagues; 2017. https://www.tobaccocontrolscale.org/ TCS2016.pdf. Accessed July 23, 2020.

39. Joossens L, Raw M. The Tobacco Control Scale 2010 in Europe. Brussels: Association of European Cancer Leagues. https://www.tobaccocontrolscale.org/TCS2010. pdf. Accessed July 23, 2020.

40. Ngo A, Cheng KW, Chaloupka FJ, Shang C. The effect of MPOWER scores on cigarette smoking prevalence and consumption. Prev Med. 2017;105:S10-S14. doi:10.1016/j.ypmed.2017.05.006

41. Dubray J, Schwartz R, Chaiton M, O'Connor S, Cohen J. The effect of MPOWER on smoking prevalence. Tob Control. 2015;24:540-542. doi:10.1136/tobaccocontrol-2014-051834

42. Moher D, Liberati A, Tetzlaff J, Altman D, The PRISMA Group. Preferred reporting items for systematic reviews and meta-analyses: The PRISMA statement. PLoS Med. 2009;6(7):e1000097. doi:10.1371/journal.pmed.1000097

\section{CONFLICTS OF INTEREST}

The authors have completed and submitted the ICMJE Form for Disclosure of Potential Conflicts of Interest and none was reported.

\section{FUNDING}

$\mathrm{AF}, \mathrm{MF}, \mathrm{CM}$, and $\mathrm{EF}$ were supported by the Ministry of Research and Universities from the Government of Catalonia [2017SGR319]. EF was also supported by the Instituto de Salud Carlos III, Government of Spain, co-funded by the European Regional Development Fund (FEDER) [INT16/00211 and INT17/00103]. CM was also supported by the Instituto de Salud Carlos III, Government of Spain, co-funded by the European Regional Development Fund (FEDER) [INT17/00116] and Ministry of Health from the Government of Catalonia [PERIS No. 9015586920/2017]. We thank CERCA Programme/Generalitat de Catalunya for institutional support.

\section{AUTHORS' CONTRIBUTIONS}

Study design: $A F, A B, C M$, and $E F$. Collected data and prepared database for analysis: $A F$ and $A B$. Contributed to strategy of analysis: $A F, A B, C M$, and EF. Analyzed data: AF. Interpreted data results: $A F, A B, C M, D, M F$, $A P$, and EF. Drafted manuscript: AF. Critically revised manuscript: All authors. Approved final manuscript version: All authors. Guarantors: $E F$ and $\mathrm{CM}$.

\section{PROVENANCE AND PEER REVIEW}

Not commissioned; externally peer reviewed. 